\title{
Investigating the Six-Month Incidence Rate of Burn Disease in Children in Greece
}

Ilias Tsiampouris ${ }^{1}$, Maria Charcharidou ${ }^{2}$, Evangelos Dousis ${ }^{1}$, Niki Oikonomidi ${ }^{1}$, Panagiota Makrygianni ${ }^{3}$ , Georgios Vasilopoulos ${ }^{1}$, Ourania Castana ${ }^{4}$, Ioannis Koutelekos ${ }^{1}$

1. Nursing, University of West Attica, Athens, GRC 2. Nursing, General Hospital of Athens "Georgios Gennimatas", Athens, GRC 3. Intensive Care Unit, General Oncology Hospital of Kifissia, Athens, GRC 4. Plastic and Reconstructive Surgery, Evangelismos General Hospital, Athens, GRC

Corresponding author: Ilias Tsiampouris, iliastsiampour@yahoo.gr

\section{Abstract \\ Introduction}

Burns in children are painful, can be fatal, and involve a significant risk of complications, along with physical and psychological consequences. This study aimed to investigate the incidence of burns in children, for six months, and the most common causative factors, along with the existing correlations between demographic data and the characteristics of burn injuries.

\section{Methods}

The study was descriptive and prospective, and the sample consisted of minors up to 14 years old with burns in any areas of the body. The research was carried out in the Attica pediatric hospitals' selected departments for six months (from July to December 2018). Sources for completing the created database were the patients, their guardians, and their medical-nursing documentation and records.

\section{Results}

The cumulative six-month incidence rate of childhood burn disease was $4.9 \%$. The most affected age group appeared to be younger than two years (60\%), while liquid heat appeared to be the primary form of the burn factor (76\%). The average duration of hospitalization for children with a deep partial-thickness to a totalthickness burn degree was 16.5 days. The correlations that emerged related to the extent of the burn were directly related to the accident's site, and patients with an increased likelihood of future additional surgeries had an increased mean total body surface area that was burned.

\section{Conclusion}

Continuous surveillance and removal of hazardous materials from the home environment is of utmost need. Early education/understanding of correct behaviors and proper attention to outdoor activities or excursions can significantly reduce burns. Training courses on burn prevention for parents are needed, as the best form of treatment is prevention.

Review began 10/12/2020 Review ended 10/14/2020 Published 10/27/2020

\section{() Copyright 2020}

Tsiampouris et al. This is an open access article distributed under the terms of the Creative Commons Attribution License CC-BY 4.0., which permits unrestricted use, distribution, and reproduction in any medium, provided the original author and source are credited.
Categories: Other, Epidemiology/Public Health, Trauma

Keywords: burns, children, incidence, injuries, burn disease

\section{Introduction}

Burn disease is a serious health condition that can affect multiple systems of the body simultaneously and may lead to acute death and significant mortality [1]. Above all else, it creates a remarkable impact on the patient's health and the finances of the patients and their families. This makes it challenging to address, and the treatment outcome is critical, not only for adult patients but also for pediatric patients. Burns are among the most common accidents that can occur to children, affecting a fairly large proportion of minors worldwide [2].

In the international literature, studies researching the incidence of burns in children are insufficient [3]. In Greece, burns in minors account for a relatively small but significant number of cases but without proven rates that have been recorded in a common database. Because there is a lack of such studies in Greece, the present study will contribute to further recording and understanding and set goals for the prevention of burn injuries in children, thus demonstrating its importance and need.

\section{Materials And Methods}

\section{Research design}

The present study was descriptive-prospective, and the sample consisted of minors up to 14 years old with 
burns in any bodily areas. The research was conducted over six months (from July to December 2018) in selected surgical departments or intensive care unit (ICU) departments of the Attica pediatric hospitals “Athens General Children’s Hospital Panagiotis and Aglaia Kyriakou” and “Athens General Children's Hospital Agia Sophia.” The demographic-socioeconomic data for the children with burns, the causes and conditions of the burn injuries, the data that determined the severity of burns, and the disease's outcome were recorded. Finally, an attempt was made to investigate the association between burns' severity and the demographic and socioeconomic data for the patients.

\section{Data collection process}

The research was carried out after the study's permits were obtained from the pediatric hospitals of Attica. The study start date was July 1, 2018, while the expiration date was December 31, 2018. Daily, over six months, new admissions of burn patients to the pediatric hospitals of Attica's specialized departments that complied with the study's criteria were eligible to participate. The patient's parents or guardians were informed, and then admission to the study proceeded once written consent was received. At the same time, the total number of patients in these specialized departments was recorded daily, and their respective data were entered into the database once informed consent was obtained. Finally, according to the medical record, the date of the patients' departure, and the outcome of the disease were recorded.

\section{Database}

A database was created to collect the following data: demographic-socioeconomic data for children with burn injuries, causes, and circumstances leading to the accident, data identifying the severity of burns, and patient outcome. Resources for filling in the database were patients and their caregivers, medical-nursing documentation forms, and medical records. To assess the severity of the burn, the Lund and Browder map was used to estimate the extent of the burn injuries, and the classification of the depth of the burn was based on clinical evaluation from the medical records [4].

The Lund and Browder map is a useful burn management tool for assessing the total body surface area (TBSA) affected by a burn. It was devised by Charles Lund, a surgeon at Boston City Hospital, and Dr. Newton Browder and was based on their experience in treating over 300 attendees who were injured in a fire at the Cocoanut Grove nightclub in Boston on November 28, 1942. Contrary to Wallace's rule of nines, the Lund and Browder map takes into account the age of the person, and thus, the percentage of the TBSA for the head is lowered, and the percentage of the TBSA for the feet is increased as a child grows, making it more useful for burns in pediatric patients [4].

\section{Sample of the study}

The study sample consisted of patients up to age 14 with any burn injury type, from partial thickness to full thickness, anywhere on their body. The sample collection was carried out in Attica's pediatric hospitals, specifically, in both ICU departments for children at the hospitals, A and B Surgical Department of the “Aglaia Kyriakou” Hospital and the Plastic Surgery Department of the “Agia Sofia” Hospital.

The patient was included in the study if he or she met the study's inclusion criteria, which were as follows: (i) boys and girls younger than 14 years old, (ii) patients with burn disease, and (iii) patients with guardians who were able to understand the purpose and process of the study and signed the informed consent form. Patients and their guardians who did not meet the inclusion criteria were excluded from the study.

Over six months, 513 children were admitted to the selected hospitals, 36 of whom had burn injuries. Of the 36 cases, 11 could not be included in the study, as they did not meet the entry criteria. In particular, all 11 of these cases were dismissed because of their burn injuries' insignificant condition.

\section{Ethics}

The current study was accepted by the Scientific Committees of both hospitals (with the decision 221/26.04.2018 for Panagiotis and Aglaia Kyriakou Hospital, and 13005/24-05-2018 for Agia Sophia Hospital) and was conducted under the principle of data protection and confidentiality. The ethical principles, as set out in the Helsinki Declaration, were followed.

Corresponding authorization was also granted by the appropriate committee of the University of Western Attica, formerly known as the Technological Educational Institute of Athens, under the supervision of the Postgraduate Program "Wound Care and Treatment."

\section{Statistical analysis}

Mean, standard deviation, median, and interquartile ranges were used to describe the quantitative variables. Absolute (N) and relative (\%) frequencies were used to describe the qualitative variables. Fisher's exact test was used to compare the proportions. Student's t-test was used to compare quantitative variables between the two groups. To compare quantitative variables between more than two groups, the parametric analysis 


\section{Cureus}

of variance was used. Significance levels were two-sided, and statistical significance was set at 0.05. IBM SPSS Statistics for Windows, Version 22.0 (IBM Corp., Armonk, NY) was used for statistical analysis.

\section{Results \\ Descriptive results}

During the six-month study period (i.e., July through December 2018), 513 children were admitted to the selected hospitals; out of them 25 , with burn injuries, were selected for the study. The six-month incidence rate or cumulative incidence of childhood burn disease was $4.9 \%$. Boys accounted for $76 \%$ of the children. The age of children with burn injuries ranged from 11 months to 14 years, with a mean of 3.6 years (standard deviation [SD], 4.0 years). Seventy-two percent of the children were Caucasian and were also of Greek nationality. Fifty-six percent of children lived in Attica, and the remaining $44 \%$ lived in a remote/rural region. Sixty percent of the children attended nursery school.

Nevertheless, $84 \%$ of the children were members of a nuclear family. None of the children had comorbidity, mental disorders, motor problems, or mental illness. The demographic data for children with burn injuries and their backgrounds are presented in Table 1. 


\section{Cureus}

\begin{tabular}{|c|c|c|c|}
\hline Demographic data & & $\mathbf{N}$ & $\%$ \\
\hline \multirow{2}{*}{ Sex } & Male & 19 & 76.0 \\
\hline & Female & 6 & 24.0 \\
\hline \multirow{2}{*}{ Age (years) } & $<2$ years & 15 & 60.0 \\
\hline & $\geq 2$ years & 10 & 40.0 \\
\hline \multicolumn{2}{|l|}{ Age (years), mean (SD); median (interquartile range) } & $3.6(4.0)$ & $1.6(1-5.5)$ \\
\hline \multirow{3}{*}{ Race } & Caucasian & 18 & 72.0 \\
\hline & Colored & 6 & 24.0 \\
\hline & Other & 1 & 4.0 \\
\hline \multirow{2}{*}{ Citizenship } & Greek & 18 & 72.0 \\
\hline & Foreigner & 7 & 28.0 \\
\hline \multirow{2}{*}{ Place of residence } & Attica & 14 & 56.0 \\
\hline & Remote region & 11 & 44.0 \\
\hline \multirow{6}{*}{ Patient's educational level } & Nursery school & 15 & 60.0 \\
\hline & Day nursery school & 1 & 4.0 \\
\hline & Pre-kindergarten & 1 & 4.0 \\
\hline & Kindergarten & 4 & 16.0 \\
\hline & Primary school & 2 & 8.0 \\
\hline & High school & 2 & 8.0 \\
\hline \multirow{3}{*}{ Patient's marital status } & Nuclear family & 21 & 84.0 \\
\hline & Extended family & 1 & 4.0 \\
\hline & Single-parent family & 3 & 12.0 \\
\hline Existence of co-morbidity & & 0 & 0.0 \\
\hline Existence of mental disorders & & 0 & 0.0 \\
\hline Existence of motor problems & & 0 & 0.0 \\
\hline Existence of mental disorders & & 0 & 0.0 \\
\hline
\end{tabular}

\section{TABLE 1: Patient demographics}

The mean hospital stay was 16.5 days (SD 12.2 days). The majority of children (72\%) were transferred to the hospital by private means of transportation. Information on the children's hospitalization is provided in Table 2 .

\section{Transferring and hospitalization records}

Duration of hospitalization (days), mean (SD); median (interquartile range)

Ambulance

Mean of transport
$16.5(12.2) \quad 14.5(8-21)$

7
28.0

72.0

TABLE 2: Patient's transferring and hospitalization records 


\section{Cureus}

All children had thermal burn injuries. Eighty-eight percent of children had a mixed depth of burn injuries, and the same percentage had multiple burned areas. Only one child had an inhalant burn injury. The mean area of burn injury was $16.9 \%$ (SD 8.8\%). Information on the children's burn injuries is provided in Table 3 .

\begin{tabular}{|c|c|c|c|}
\hline \multicolumn{2}{|l|}{ Burn injury data } & $\mathbf{N}$ & $\%$ \\
\hline Type of burn injury & Thermal & 25 & 100.0 \\
\hline \multirow{2}{*}{ Depth of burn injury } & Deep partial thickness & 3 & 12.0 \\
\hline & Mixed depth & 22 & 88.0 \\
\hline \multirow{2}{*}{ Multiple burned areas } & No & 3 & 12.0 \\
\hline & Yes & 22 & 88.0 \\
\hline \multirow{2}{*}{ Existence of inhalation $b$} & No & 24 & 96.0 \\
\hline & Yes & 1 & 4.0 \\
\hline Mean area of burn injury (\%), mean (SD) & & 16.5 & \\
\hline
\end{tabular}

TABLE 3: Patient's burn injury data

The most frequent burn injuries were on the trunk's anterior surface, neck, head, and anterior surface of the right hand with $64.0 \%, 56.0 \%, 44.0 \%$, and $40.0 \%$, respectively. Table 4 provides a detailed breakdown of the children's burn injuries in a descending order. 


\section{Cureus}

\begin{tabular}{|c|c|c|}
\hline Body area & $\mathbf{N}$ & $\%$ \\
\hline Anterior trunk surface & 16 & 64.0 \\
\hline Neck & 14 & 56.0 \\
\hline Head & 11 & 44.0 \\
\hline Right hand anterior surface & 10 & 40.0 \\
\hline Left hand anterior surface & 8 & 32.0 \\
\hline Right hand rear surface & 6 & 24.0 \\
\hline Trunk rear surface & 5 & 20.0 \\
\hline Right foot anterior surface & 5 & 20.0 \\
\hline Left foot anterior surface & 5 & 20.0 \\
\hline Buttocks & 4 & 16.0 \\
\hline Left hand rear surface & 3 & 12.0 \\
\hline Right foot rear surface & 3 & 12.0 \\
\hline Left foot rear surface & 3 & 12.0 \\
\hline Right palm outer surface & 2 & 8.0 \\
\hline Right palm inner surface & 2 & 8.0 \\
\hline Perinatal area & 2 & 8.0 \\
\hline Right foot outer surface & 2 & 8.0 \\
\hline Left foot outer surface & 2 & 8.0 \\
\hline Left palm exterior surface & 1 & 4.0 \\
\hline Left palm inner surface & 1 & 4.0 \\
\hline Right insole inner surface & 1 & 4.0 \\
\hline Left insole inner surface & 1 & 4.0 \\
\hline
\end{tabular}

\section{TABLE 4: Patient's burn injuries in a descending order}

The main cause of burn injuries was wet heat (76.0\%). The most common household location where the injury occurred was the kitchen, with a $60.0 \%$ rate, and most accidents occurred either at noon or in the morning, with rates of $48.0 \%$ and $36.0 \%$, respectively. Table 5 provides information on the accident that caused the burn injuries, while Table 6 provides data on the treatment and the therapy outcome. 


\section{Cureus}

\begin{tabular}{|c|c|c|c|}
\hline Accident information & & $\mathbf{N}$ & $\%$ \\
\hline \multirow{3}{*}{ Cause of burn } & Dry heat & 4 & 16.0 \\
\hline & Wet heat & 19 & 76.0 \\
\hline & Hot object & 2 & 8.0 \\
\hline \multirow{4}{*}{ Accident area } & Kitchen & 15 & 60.0 \\
\hline & Bathroom & 2 & 8.0 \\
\hline & Living room & 5 & 20.0 \\
\hline & Outdoors & 3 & 12.0 \\
\hline \multirow{4}{*}{ Time during the day the accident occurred } & Morning & 9 & 36.0 \\
\hline & Midday & 12 & 48.0 \\
\hline & Afternoon & 3 & 12.0 \\
\hline & Night & 1 & 4.0 \\
\hline
\end{tabular}

\section{TABLE 5: Accident information}

\begin{tabular}{|c|c|c|c|}
\hline \multicolumn{2}{|c|}{ Patient's treatment and therapy outcome data } & $\mathbf{N}$ & $\%$ \\
\hline \multirow{2}{*}{ Treatment of burn injuries } & Conservative therapy & 23 & 92.0 \\
\hline & Surgical therapy & 2 & 8.0 \\
\hline \multirow{2}{*}{ Skin transplant } & No & 24 & 96.0 \\
\hline & Yes & 1 & 4.0 \\
\hline \multirow{2}{*}{ Type of implant } & Autograft & 1 & 4.0 \\
\hline & None & 24 & 96.0 \\
\hline \multirow{2}{*}{ Signs of infection } & No & 25 & 100.0 \\
\hline & Yes & 0 & 0.0 \\
\hline \multirow{2}{*}{ Possibility of future addition } & No & 18 & 72.0 \\
\hline & Yes & 7 & 28.0 \\
\hline \multirow{5}{*}{ Final outcome } & Complete cure & 5 & 20.0 \\
\hline & Discharge with continuous observation & 15 & 60.0 \\
\hline & Discharge with scheduled readmission & 2 & 8.0 \\
\hline & Death & 0 & 0.0 \\
\hline & Patient stayed after completion of investigation & 3 & 12.0 \\
\hline
\end{tabular}

TABLE 6: Patient's treatment and therapy outcome data

Correlation of burn extent, demographic data for children, and burn injury data

The extent of children's burn injuries was similar concerning their demographics. Table 7 provides information on the extent of children's burns according to their demographics. 


\section{Cureus}

\begin{tabular}{|c|c|c|c|c|}
\hline \multirow{2}{*}{ Patients demographics } & & \multicolumn{2}{|c|}{ Extent of burned body area (\%) } & \multirow{2}{*}{ p, Student's t-test } \\
\hline & & Mean & SD & \\
\hline \multirow{2}{*}{ Sex } & Male & 18.4 & 8.4 & \multirow{2}{*}{0.147} \\
\hline & Female & 12.3 & 9.5 & \\
\hline \multirow{2}{*}{ Age (years) } & $<2$ & 16.7 & 7.4 & \multirow{2}{*}{0.851} \\
\hline & $\geq 2$ & 17.4 & 11.0 & \\
\hline \multirow{2}{*}{ Race } & Caucasian & 16.0 & 9.9 & \multirow{2}{*}{0.423} \\
\hline & Black/Other & 19.2 & 5.4 & \\
\hline \multirow{2}{*}{ Citizenship } & Greek & 16.8 & 9.2 & \multirow{2}{*}{0.894} \\
\hline & Foreigner & 17.3 & 8.5 & \\
\hline \multirow{2}{*}{ Nuclear type of family } & No & 20.5 & 7.5 & \multirow{2}{*}{0.389} \\
\hline & Yor & $10 ?$ & 01 & \\
\hline
\end{tabular}

\section{TABLE 7: Correlation of burn injury extent and demographics data}

It is worth mentioning that the burned area was significantly higher in children who experienced an accident outdoors, with an average burned TBSA rate of $29.0 \%$, compared to children who received burns inside their home, with a mean burned TBSA rate of $15.3 \%$. $(p=0.008)$. Nevertheless, a significantly higher range of burned area was found in children treated with surgery, with an average burned TBSA rate of $30.0 \%$ $(p=0.026)$, as well as those who were likely to have future additional surgeries, with a mean burned TBSA rate of $25.1 \%$ ( $p=0.002$ ). Table 8 shows the extent of children's burn injuries according to their burn data.

\begin{tabular}{|c|c|c|c|c|}
\hline \multirow{2}{*}{ Burn injury data } & & \multicolumn{2}{|c|}{$\begin{array}{l}\text { Extent of burned } \\
\text { body area (\%) }\end{array}$} & \multirow{2}{*}{$\begin{array}{l}\text { p, } \\
\text { Student's } \\
\text { t-test }\end{array}$} \\
\hline & & Mean & SD & \\
\hline \multirow{3}{*}{ Cause of burn } & Dry heat & 25.1 & 11.1 & \multirow{3}{*}{0.119} \\
\hline & Wet heat & 15.1 & 8.0 & \\
\hline & Hot object & 17.5 & 3.5 & \\
\hline \multirow{2}{*}{ Accident area } & Home & 15.3 & 7.5 & \multirow{2}{*}{0.008} \\
\hline & Outdoors & 29.0 & 10.1 & \\
\hline \multirow{2}{*}{ Treatment } & Conservative treatment & 15.8 & 7.7 & \multirow{2}{*}{0.026} \\
\hline & Surgical treatment & 30.0 & 14.1 & \\
\hline \multirow{2}{*}{$\begin{array}{l}\text { Possibility of future } \\
\text { additional surgeries }\end{array}$} & No & 13.7 & 7.1 & \multirow{2}{*}{0.002} \\
\hline & Yes & 25.1 & 7.8 & \\
\hline \multirow[b]{2}{*}{ Final ot } & Complete cure & 14.4 & 6.6 & \multirow[b]{2}{*}{0.48} \\
\hline & $\begin{array}{l}\text { Discharge with continuous observation/discharge with scheduled } \\
\text { readmission/patient stayed after completion of investigation }\end{array}$ & 17.6 & 9.3 & \\
\hline
\end{tabular}

TABLE 8: Correlation of burned body area extent and burn injury data

Correlation of outcome, demographic data, and burn injury treatment data 
The outcomes of the children, according to the data collected, were not significantly different. Table 9 shows the outcome of the children according to their demographics and the data related to the treatment of burns.

\begin{tabular}{|c|c|c|c|c|c|c|}
\hline \multirow{3}{*}{\multicolumn{2}{|c|}{$\begin{array}{l}\text { Patient demographics and treatment } \\
\text { data }\end{array}$}} & \multicolumn{4}{|c|}{ Patient's outcome } & \multirow{3}{*}{$\begin{array}{l}\text { p, Fisher's } \\
\text { exact test }\end{array}$} \\
\hline & & \multicolumn{2}{|c|}{$\begin{array}{l}\text { Complete } \\
\text { cure }\end{array}$} & \multicolumn{2}{|c|}{$\begin{array}{l}\text { Discharge with continuous observation/discharge with scheduled } \\
\text { readmission/patient stayed after completion of the investigation }\end{array}$} & \\
\hline & & $\mathrm{N}$ & & $\mathrm{N}$ & $\%$ & \\
\hline \multirow{2}{*}{ Sex } & Male & 3 & 15.8 & 16 & 84.2 & \multirow{2}{*}{0.562} \\
\hline & Female & 2 & 33.3 & 4 & 66.7 & \\
\hline \multirow{2}{*}{ Age (years) } & $<2$ & 3 & 20.0 & 12 & 80.0 & \multirow{2}{*}{1.000} \\
\hline & $\geq 2$ & 2 & 20.0 & 8 & 80.0 & \\
\hline \multirow{2}{*}{ Race } & Caucasian & 4 & 22.2 & 14 & $7 / .8$ & \multirow{2}{*}{1.000} \\
\hline & Black/Other & 1 & 14.3 & 6 & 85.7 & \\
\hline \multirow{2}{*}{ Citizenship } & Greek & 4 & 22.2 & 14 & 77.8 & \multirow{2}{*}{1.000} \\
\hline & Foreigner & 1 & 14.3 & 6 & 85.7 & \\
\hline \multirow{2}{*}{ Treatment } & $\begin{array}{l}\text { Conservative } \\
\text { treatment }\end{array}$ & 4 & 17.4 & 19 & 82.6 & \multirow{2}{*}{0.367} \\
\hline & $\begin{array}{l}\text { Surgical } \\
\text { treatment }\end{array}$ & 1 & 50.0 & 1 & 50.0 & \\
\hline \multirow{2}{*}{$\begin{array}{l}\text { Possibility of future } \\
\text { additional surgeries }\end{array}$} & No & 5 & 27.8 & 13 & 72.2 & \multirow{2}{*}{0.274} \\
\hline & Yes & 0 & 0.0 & 7 & 100.0 & \\
\hline
\end{tabular}

TABLE 9: Correlation of patient's outcome, demographic, and treatment data

\section{Discussion}

This study's cumulative incidence was determined to be $4.9 \%$ for the study period for children who required hospitalization in pediatric hospitals. Although there are no similar surveys in Greece to compare the results, nor are there similar, relatively recent, European country surveys, similar studies have been conducted in other countries worldwide, and our results appear to be quite close to them. Specifically, in 2016, in a US study, burn incidence for 1998 to 2013 was determined, in which severe thermal burn injuries were included, just as in the present Greek study, at 2.15\% [5]. In contrast was a 2017 study for 2000 to 2014 in Brazil, with an incidence at $14.56 \%$ that included children under the age of five years who accounted for $24 \%$ of imports [6], while for 2016, a similar proportion was also found in the Zuni region of southwestern China, with an impact of $12.7 \%$ [7]. It should be noted that the burn incidence of the present study was equal (4.9\%) to that of the city Riyadh of Saudi Arabia for 2013 [8].

Of the 25 cases in the present study, $76 \%$ were boys $(n=19)$, and $24 \%$ were girls $(n=6)$. Similar results have been obtained in various studies worldwide, such as in one study in Croatia in 2015, with boys accounting for $64.15 \%$ and girls accounting for $35.85 \%$ [9]. In the United States in 2016, boys accounted for 68\%, and girls accounted for 32\% [10], and in other countries such as Bangladesh [11], Kenya [12], and Nigeria [13], the highest number of cases was for boys. However, the distribution of nonfatal serious burn injuries by sex varies between countries. In some countries, such as Egypt and India, a higher rate of burn injuries was obtained for girls [14]. Pediatric patients consisted of $72 \%$ Caucasian and $24 \%$ other races, with rates similar to those reported by the American Burn Association in 2016 [10].

Fifty-six percent of the cases in the current study lived in the urban area of Attica, compared to $44 \%$ who lived outside of Attica, which is roughly the same as figures from the United States ( $54 \%$ for urban and $46 \%$ for remote/rural areas) [15] and similar to a 2015 Croatian survey, where $67 \%$ of cases resided in an urban area, compared to 33\% in a rural area [9]. Finally, in 2015, an Australian study for 2008 to 2012 accounted for $21.2 \%$ of incidents from rural areas compared to $78.8 \%$ of incidents from urban areas [16].

Although $84 \%$ of the sample in the current study belonged to a nuclear family, as opposed to $12 \%$ who belonged to a single-parent family, and there were no children in the sample who had comorbidities, mental 
disorders, motor problems, or mental illness, after searching the international bibliography, there was not a single previous study that investigated the correlation of burn injuries and patients' marital status or the presence of concomitant diseases.

The average length of hospitalization for children with deep partial-thickness to total-thickness burn injuries was 16.5 days. Similar rates appeared in a South Korean study, with a mean hospital stay of seven days [17], and in an Australian study, with a mean hospital stay of three days [18]. In contrast, a similar study in central China showed that pediatric patients required an average length of stay of 52.3 to 40.2 days [19], while in Croatia, the mean hospital stay was 174.5 days [9].

Children under the age of two years represented $60 \%$ of the study $(n=15)$, while children over the age of two represented $40 \%(n=10)$. Although several studies worldwide reported that most burn injuries occurred in children under the age of two, there are studies with similar rates, such as a Beijing study, in which $47.8 \%$ were children over the age of two and $52.2 \%$ were under the age of two [20], and an Indian study, where it was shown that $50.1 \%$ of participants were over two years old and $49.9 \%$ were younger than two years [21].

All 25 cases (100\%), which met the criteria for entry into our study, were treated for heat burn, unlike worldwide studies where the sample differed due to the presence of an electrical or chemical agent. Only $12 \%(n=3)$ had deep partial-thickness burns, as opposed to the very high $88 \%(n=22)$, with mixed-depth burn injuries (mainly total thickness as well as deep partial-thickness). A literature review found only two studies reporting the rates of tissue damage depth, consisting of a Central China study in 2017, where a lower percentage of total-thickness burn injuries, at 59.3\%, and a higher percentage of partial burn injuries, at $40.7 \%$, were shown [19], and an Indian study in 2017 that showed that $49.5 \%$ had partial-thickness burn injuries, while $41.9 \%$ had mixed-thickness burn injuries [21]. At the same time, a 2016 study in England only reported the incidence of severe thermal burn injuries of full-thickness, without reporting the proportion of children [5].

Eighty-eight percent $(n=22)$ of the current study cases had multiple burned areas, as opposed to $12 \%(n=3)$, where burn injury occurred on only one part of their body. A study in Morocco found that the proportion of children burned in more than one area was $69.03 \%$ [22].

Inhalation burn injury accounted for $4 \%$ of the sample in the present study, which corresponds to only one patient. Its incidence is much higher in overseas studies, as the recording time is longer, making the study sample significantly larger.

The mean burned area in this study was $16.9 \%$. In studies abroad, there was a rating of $5 \%$ in a Saudi Arabian study [8], 5.5\% in a Moroccan study [22], $19.73 \pm 15 \%$ in an Iraqi study [23], and $37 \pm 24 \%$ in an Indian study [21]. The three main areas of the body that suffered burn injuries, in a descending order of incidence, are the trunk's anterior surface with $64 \%$, the neck with $56 \%$, and the head with $44 \%$. In contrast to a study in South Korea the same year, the most frequently injured area of the child's body, in the descending order, was the upper limbs, lower limbs, and body trunk, with no percentages, reported [17]. However, a study from Saudi Arabia listed face, chest, and knees as the most common sites of burn injuries [8].

The burn accident's primary cause was $76 \%$ due to wet heat, followed by $16 \%$ caused by dry heat, and $8 \%$ due to contact with hot objects. Wet heat appears to remain first, as shown in a 1996 burn injury study in France with $64.1 \%$ and $16.95 \%$ for volatile fluids [24]. Similar results were found in studies conducted in Peru in 2002, with wet heat accounting for 74\% of the cases [25], Bradford in 2007 (52\%) [26], Morocco in 2013 (83.5\%) [22], and India in 2017 (48.8\%), followed by dry heat (43.4\%) [21].

Our survey showed that most burn injuries occurred at home (88\%), compared to $12 \%$ for outdoor burn injuries. In particular, $60 \%$ of accidents occurred in the kitchen, $20 \%$ occurred in the living room, and $8 \%$ occurred in the bathroom. The 1996 French study agrees once more with the present data, stating that the kitchen is the most dangerous area of the house, with $56.2 \%$ occurrence, while the bathroom is in second place with 13.6\% [24]. Despite a 10-point difference, a Peruvian study also showed that most accidents occur at home (77.5\%), and the most common area where accidents occur was the kitchen (67.8\%) [25]. According to a South Korean study, the majority of burns took place indoors, with the home being the most common area (85.8\%), and more specifically, the kitchen/dining area comprising 58.8\%, living room $23.3 \%$, bedroom 11.4\%, and bathroom 5.1\% [17]. A sub-Saharan African study showed that almost $89.2 \%$ of pediatric cases were injured at home [27], while a study conducted in Riyadh showed that burn injuries caused at home accounted for $35 \%$, compared to $2.7 \%$ that occurred outside the home [8]. In contrast, a study in England in 2007 showed that $85 \%$ of burn injuries had occurred in nature/the outdoors [26].

Most of the accidents in our study occurred in the morning and midday, at $36 \%$ and $48 \%$, respectively. During the afternoon, $12 \%$ of the accidents occurred, while in the evening, there was only one incident, with the rate reaching $4 \%$. Only one transcontinental study reported that the two principal hours in which accidents occurred were late morning and afternoon [28].

The leading cause of burn injuries appeared to be due to hot liquids in the kitchen or living room at $72 \%$, 
including water, beverages, food, or oil. Thereafter, the cause appeared to be the child in $12 \%$ of cases, due to a lack of adult supervision in the same room. The third cause was bathing for $8 \%$, and the last was home fires at $8 \%$, due to external or internal factors. To the best of our knowledge, there has been no similar study in the international literature that investigated the accident's cause and the extent of patient involvement in causation.

Most children (92\%) received conservative treatment, while $8 \%$ underwent surgical treatment. Only one child (4\%) received a transplant, and autografts were used in particular, while $28 \%$ of children were candidates for future additional surgeries. In other studies, 35\% of patients required a skin graft [24], while another study found that children living in a rural area required a skin graft in $28.3 \%$ of cases, as opposed to children who were residents of urban areas, of whom $16.3 \%$ required a skin graft [16]. In another study, it was observed that over 10 years from 2003 to 2013, the need for skin grafts decreased from $18 \%$ to only $5 \%$ [29].

The outcome was that $60 \%$ of the patients were discharged with continuous follow-up, while $8 \%$ had been discharged with a scheduled reintroduction to perform surgeries. In a study by the Australian and New Zealand Burn Association in 2017, almost twice as many (14\%) children were re-admitted within 28 days of the discharge day, with the majority (77\%) reported as planned reintroduction [18].

The correlation of the extent of children's burn injuries and their demographics showed that the extent of burn injuries was similar for each child's differentiation data, with no noticeable difference. However, the correlation between the extent of burn injuries and the burn injury data was statistically significant. Specifically, the extent of the burn injury was directly related to the accident site, with the mean value of the burned TBSA at-home accidents being $15.3 \%$, compared to $29 \%$ for accidents occurring outdoors $(p=0.008)$. At the same time, the mean value of the extent of the burned area was statistically significant $(p=0.026)$, as patients with conservative treatment had a mean burned TBSA of $15.8 \%$, compared to patients who underwent surgical treatment, who had $30 \%$ of the average burned TBSA.

Finally, there was statistical significance $(\mathrm{p}=0.002)$ among those who had an increased likelihood of future additional surgeries, with a mean burned TBSA of $25.1 \%$, as opposed to those who did not have such a probability, with an average burned TBSA of $13.7 \%$. As far as we are aware, this specific association (burn area-demographic burn-out data) and the concerned data haven't been studied before.

Correlating the outcome with patient demographics and the treatment of burn injuries, pediatric patients' outcomes did not significantly differ, with the data being shared between differentiation data. To our knowledge, no studies were found to examine this specific association (patient outcome-demographic-burnout) and present their data.

\section{Study limitations}

This study was subject to methodological limitations. The sample size of the study, although small, is a convenience sample and is not representative of the population to yield sufficient statistically significant results. The present study would probably require a longer time to record more cases and observe the sample. The information collected relates to pediatric patients with burn disease treated in the selected hospitals and not to those who came to the emergency departments. Finally, the sample that was recorded concerned only data from the Prefecture of Attica's pediatric hospitals, specifically, the Athens General Children’s Hospital “Panagiotis and Aglaia Kyriakou” and Athens General Children's Hospital “Agia Sophia.”

\section{Conclusions}

The acquisition of burns and the severe effects they may have on childhood and their impact on human life have prompted research questions to be initiated. Boys seem to be more prone to burn accidents related to the lively side of their nature. Infants and toddlers seem to be more prone to exploring and discovering the area around them, but unfortunately, they are unaware of the dangers that could lead to an accident. In neither case can special precautionary or preventive measures be taken except to recommend the continuous surveillance and monitoring of children inside and outside the home, to remove hazardous materials that may cause combustion, chemical burns, or electric shocks, as well as informing children early on regarding proper behavior, what is dangerous, what the results can be, and what can cause serious injuries to them.

Most accidents seemed to occur inside the home and mainly in the kitchen, when cooking was being conducted, and while parents were in the same room. Parents should make sure that children do not enter the kitchen during cooking, or when they enter, that their safety is ensured. A parent should never hold a child in his or her arms while they cook because children tend to explore the area around them and can cause an accident. Therefore, it seems training courses on burn prevention for parents are needed, as the best form of treatment is prevention. Lastly, burn accidents caused outdoors appeared to cause more extensive burn injuries at both the surface and depth. Parents and children should pay particular attention when going on nature trips and setting up improvised fireplaces, as severe burns can easily result from such fires. 
When considering the higher validity and reliability of the results, it is clear that there is an urgent need to design future studies that will provide a larger sample that is representative of the population and be carried out for a more extended period of time so that they can produce sufficient important statistical results. At the same time, the information should be collected for the entire pediatric population through primary and secondary education (schools) or emergency departments to record more cases, even those that do not require hospitalization. Future studies should compare the results between two towns or at least the incident recordings, go beyond the scope of a region, and be conducted within a geographical department or even the entire country.

\section{Additional Information \\ Disclosures}

Human subjects: Consent was obtained by all participants in this study. Animal subjects: All authors have confirmed that this study did not involve animal subjects or tissue. Conflicts of interest: In compliance with the ICMJE uniform disclosure form, all authors declare the following: Payment/services info: All authors have declared that no financial support was received from any organization for the submitted work. Financial relationships: All authors have declared that they have no financial relationships at present or within the previous three years with any organizations that might have an interest in the submitted work. Other relationships: All authors have declared that there are no other relationships or activities that could appear to have influenced the submitted work.

\section{Acknowledgements}

The authors would like to express their gratitude to the Athens General Children's Hospitals "Panagiotis \& Aglaia Kyriakou" and "Agia Sophia" for their approval of the study, as well as to all the pediatric burn patients and their families who were willing to participate in this study, after they were first informed. Furthermore, the authors would like to report that they received no external aid for completing the structure and the writing of the present study.

\section{References}

1. Bakker A, Maertens KJP, Van Son MJM, Van Loey NEE: Psychological consequences of pediatric burns from a child and family perspective: a review of the empirical literature. Clin Psychol Rev. 2013, 33:361-371. 10.1016/j.cpr.2012.12.006

2. Kemp AM, Jones S, Lawson Z, Maguire SA: Patterns of burns and scalds in children . Arch Dis Child. 2014, 99:316-321. 10.1136/archdischild-2013-304991

3. Brusselaers N, Monstrey S, Vogelaers D, Hoste E, Blot S: Severe burn injury in Europe: a systematic review of the incidence, etiology, morbidity, and mortality. Crit Care. 2010, 14:R188. 10.1186/cc9300

4. Lund CC, Browder NC: The estimation of areas of burns . Surg Gynecol Obstet. 1944, 79:352-358.

5. Baker R, Tata LJ, Kendrick D, Burch T, Kennedy M, Orton E: Differing patterns in thermal injury incidence and hospitalizations among 0-4 year old children from England. Burns. 2016, 42:1609-1616. 10.1016/j.burns.2016.05.007

6. Santos JV, Souza J, Amarante J, Freitas A: Burden of burns in Brazil from 2000 to 2014: a nationwide hospital-based study. World J Surg. 2017, 41:2006-2012. 10.1007/s00268-017-3988-5

7. Shi S, Yang H, Hui Y, et al.: Epidemiologic characteristics, knowledge and risk factors of unintentional burns in rural children in Zunyi, Southwest China. Sci Rep. 2016, 6:35445. 10.1038/srep35445

8. Alharthy N, Al Mutairi M, AlQueflie S, Nefesa AB, Manie NB, Nafesa SB, Al Zahrani FS: Pattern of burns identified in the Pediatrics Emergency Department at King Abdul-Aziz Medical City: Riyadh. J Nat Sci Biol Med. 2016, 7:16-21. 10.4103/0976-9668.175019

9. Barcot Z, Kralj R, Barcot L, Zupancic B: Pediatric burn story - retrospective 5 year study of the characteristics and epidemiology of pediatric burn injuries in the National Pediatric Burn Referral Center. Ann Burns Fire Disasters. 2015, 89:1-2.

10. Burn incidence fact sheet. (2016). Accessed: September 28, 2020: https://ameriburn.org/who-weare/media/burn-incidence-fact-sheet/.

11. Mashreky SR, Rahman A, Chowdhury SM, et al.: Consequences of childhood burn: findings from the largest community-based injury survey in Bangladesh. Burns. 2008, 34:912-918. 10.1016/j.burns.2008.05.002

12. Ndiritu S, Ngumi ZWW, Nyaim O: Burns: the epidemiological pattern, risk and safety awareness at Kenyatta National Hospital, Nairobi. East Afr Med J. 2006, 83:455-460. 10.4314/eamj.v83i8.9462

13. Gali BM, Madziga AG, Naaya HU: Epidemiology of childhood burns in Maiduguri north-eastern Nigeria . Niger J Med. 2004, 13:144-147.

14. Peck MD: Epidemiology of burns throughout the world. Part I: distribution and risk factors . Burns. 2011, 37:1087-1100. 10.1016/j.burns.2011.06.005

15. Marek AP, Nygaard RM, Cohen EM, et al.: Rural versus urban pediatric non-accidental trauma: different patients, similar outcomes. BMC Res Notes. 2018, 11:519. 10.1186/s13104-018-3639-4

16. Hyland EJ, Zeni G, Harvey JG, Holland AJA: Rural and metropolitan pediatric burns in New South Wales and the Australian Capital Territory: does distance make a difference?. J Burn Care Res. 2015, 36:e231-e237. 10.1097/BCR.0000000000000138

17. Park JM, Park YS, Park I, Kim MJ, Kim KH, Park J, Shin DW: Characteristics of burn injuries among children aged under six years in South Korea: Data from the emergency department-based injury in-depth surveillance, 2011-2016. PLoS One. 2018, 13:e0198195. 10.1371/journal.pone.0198195

18. Australian and New Zealand Burns Association: Burns Registry of Australia and New Zealand (BRANZ) . (2017). Accessed: September 30, 2020: 


\section{Cureus}

https://anzba.org.au/assets/BRANZ_AnnualReport_Year8_FINAL_V2.pdf.

19. Cheng WF, Zhao DX, Shen ZA, et al.: An epidemiological investigation of pediatric patients under 14 with large area burns: a multicenter study. (Article in Chinese). Zhonghua Yi Xue Za Zhi. 2017, 97:462-467. 10.3760/cma.j.issn.0376-2491.2017.06.013

20. Wang S, Li D, Shen C, Chai J, Zhu H, Lin Y, Liu C: Epidemiology of burns in pediatric patients of Beijing City. BMC Pediatr. 2016, 16:166. 10.1186/s12887-016-0686-7

21. Dhopte A, Tiwari VK, Patel P, Bamal R: Epidemiology of pediatric burns and future prevention strategies - a study of 475 patients from a high-volume burn center in North India. Burns Trauma. 2017, 5:1-8. 10.1186/s41038-016-0067-3

22. Droussi H, Benchamkha Y, Ouahbi S, et al.: Epidemiology and treatment of paediatric burns in a large children's hospital in Morocco: analysis of 394 cases. Afr J Emerg Med. 2013, 3:110-115. 10.1016/j.afjem.2013.04.002

23. Al-Zacko SM, Zubeer HG, Mohammad AS: Pediatric burns in Mosul: an epidemiological study . Ann Burns Fire Disasters. 2014, 27:70-75.

24. Mercier C, Blond MH: Epidemiological survey of childhood burn injuries in France . Burns. 1996, 22:29-34. 10.1016/0305-4179(95)00073-9

25. Delagado J, Ramirez-Cardich ME, Gilman RH, et al.: Risk factors for burns in children: crowding, poverty, and poor maternal education. Inj Prev. 2002, 8:38-41. 10.1136/ip.8.1.38

26. Khan AA, Rawlins J, Shenton AF, Sharpe DT: The Bradford Burn Study: the epidemiology of burns presenting to an inner city emergency department. Emerg Med J. 2007, 24:564-566. 10.1136/emi.2005.027730

27. Parizh D, Kuijs A, Nkumbi U, Rabbitts A, Heffernan J, Gallagher JJ: 467 A pediatric burn unit in Sub-Saharan Africa. J Burn Care Res. 2018, 39:S206

28. Forjuoh SN: Burns in low- and middle-income countries: a review of available literature on descriptive epidemiology, risk factors, treatment, and prevention. Burns. 2006, 32:529-537. 10.1016/j.burns.2006.04.002

29. Burgess JD, Kimble RM, Cameron CM, Stockton KA: Hot beverage scalds in Australian children: still simmering 10 years on. J Burn Care Res. 2016, 37:e335-e339. 10.1097/BCR.0000000000000267 